\title{
Epidemiology of anaphylaxis
}

Elaine Gagete Miranda da Silva, MD, PhD; Fábio F. Morato Castro, MD, PhD²

\begin{abstract}
Anaphylaxis is a hypersensitivity disease whose main features are the severity, the acute presentation and the possible progression to shock and / or respiratory failure unless the patient is immediately treated. Its prevalence is not fully known, varying according to the surveyed areas around the world, and for reasons not fully understood, its frequency and severity are increasing. Through epidemiological studies, it is possible to better investigate the disease, its triggers and associated co-factors, and its prevention. This review addresses the major epidemiological studies conducted on the topic in recent decades.
\end{abstract}

Keywords: Anaphylaxis, hypersensitivity, epidemiology, allergy, immunology.
${ }^{1}$ Dr. Elaine Gagete Miranda da Silva Clinic, Botucatu, São Paulo, Brazil.

2 Division of Clinical Immunology and Allergy, Department of Medicine, Schoo of Medicine of the University of São Paulo FMUSP, São Paulo, SP, Brazil.

\section{Correspondence:}

Elaine Gagete Miranda da Silva

E-mail: doutoraelaine@gmail.com

No conflicts of interest declared concerning the publication of this article.

Submitted Jun 152014 accepted Sep 272014.
Anaphylaxis is a severe, life-threatening, acute systemic disease, caused by hypersensitivity reaction. The first task force to define anaphylaxis happened in $1998^{1}$ and described the condition as a generalized reaction with pruritus, urticaria, angioedema, hypotension, wheezing, bronchospasm, nausea, vomiting, abdominal pain, diarrhea, uterine cramps and cardiovascular dysfunction, all together or in a combination of symptoms. At that time, distinction between anaphylactic and anaphylactoid reactions was made, according to participation or not of IgE-mediated mechanisms, respectively.

This concept, however, was too broad and led to many diagnostic mistakes and misunderstanding about the real boundaries of the disease. Therefore, it is important to keep this in mind when one analyses older epidemiological reports.
The first "Symposium on the Definition and Management of Anaphylaxis," promoted by The National Institute of Allergy and Infectious Disease and the Food Allergy and Anaphylaxis Network $\left(\right.$ NIAID/FAAN) ${ }^{2}$ was held in 2004, and it became clear the necessity of more reliable clinical parameters for diagnosis and prompt treatment of anaphylaxis. Finally, after one year NIAID/FAAN organized a second symposium to establish a definition and management procedures for anaphylaxis, ${ }^{3}$ which are still currently used, with parameters that are summarized on Table 1.

From that point on, the term "anaphylactoid" was finally abandoned, due to the false idea of a less severe reaction that was implied. Hence, anaphylactic reactions are all those that meet the diagnostic criteria, regardless their etiophatogenic mechanisms. ${ }^{4}$ 
The current definition is widely accepted and it is the basis for many anaphylaxis management guidelines. $^{5}$

Despite their worldwide use, the diagnostic criteria are not absolute. Although their sensitivity is as high as $95 \%$, its specificity is only approximately $80 \%$, what means the disease can be overestimated in 20\% of the cases $^{6}$. Campbell et al. $(2012)^{6}$ described a positive predictive value of $68.6 \%$, and a negative predictive value of $98.4 \%$, which means that presence of anaphylaxis is highly unlikely if the patient's symptoms do not fit the criteria. On the other hand, there may be a higher probability of mistake if the patient does not present the symptoms, since there may be a chance of false diagnosis. The criteria are very useful in emergency departments, since the risk of not treating an anaphylactic reaction is higher than overdiagnosing it. However, it is worth highlighting the importance of more certain diagnosis and the need for a follow up evaluation by a specialist. ${ }^{7}$

Even considering the low positive predictive value, the biggest problem nowadays is not overdiagnosing. On the contrary, we are still facing the opposite situation. Huang et al. ${ }^{8}$ investigated several DIC-9 codes related to allergic reactions, and crossed them with symptoms presented by patients in a Children Hospital Emergency Room. Codes as "Other adverse food reactions" (995.7) and "Allergic urticaria"(708.0) have been found later to actually be anaphylaxis. These authors identified that physicians in Emergency Rooms often underdiagnose patients with anaphylaxis without cutaneous symptoms. Harduar-Morano et al. ${ }^{9}$ also pointed to the lack of a specific code for anaphylactic reactions in DIC-9 and estimated that $58 \%$ of the cases were underdiagnosed, especially the ones caused by insect venom. Even DIC10 lacks codes related to anaphylaxis, and instead of a specific term for the disease, it only presents terms such as "unspecified allergy" (T78.4), "personal history of allergy to drugs, medication and biological substances" (Z88.0 to Z91.0), and "anaphylactic shock" (T78.0, T78.2, T80.5 e T88.6).

An important point is to distinguish between two definitions often used in several epidemiological studies. "Incidence" is the total number of new cases in a certain place and time, indicating how frequently a population gets a disease, and shows the probability of new occurrences in the population. "Prevalence" is the total number of people with that disease, both new and old cases. Prevalent cases are those previously diagnosed (old cases) plus the ones that were found afterwards (new cases). ${ }^{10}$ Such definitions are crucial for studying the different levels of the disease in a population, and for comparing such levels across different populations. Researching the latter also requires compatible methodologies. However, studies aimed at assessing either incidence and/or prevalence of patients with allergic reactions do not always consider the methodological variables in sources of

Table 1 - Diagnostic criteria for anaphylaxis

Anaphylaxis is highly likely when at least one of the following 3 criteria are fulfilled

1 - Acute onset of an illness (minutes to several hours) with involvement of the skin, mucosal tissue, or both, and at least one of the following:

a. Respiratory involvement (eg, dyspnea, bronchospasm, stridor, hypoxia).

b. Cardiovascular involvement (eg, hypotension, colapse).

2- Two or more of the following that occur rapidly after exposure to a likely allergen for that patient (minutes to several hours):

a. Involvement of the skin-mucosal tissue (eg, generalized hives, itch-flush, swollen lips-tongue-uvula),

b. Onset of cardiovascular symptoms,

c. Signs of involvement of the respiratory system,

d. Persistent gastrointestinal symptoms (eg, crampy abdominal pain, vomiting).

3 - Reduced blood pressure after exposure to a known allergen for that patient (minutes to several hours). Hypotension is defined as a drop in systolic pressure to levels $30 \%$ below of the basal value, or $<90 \mathrm{mmHg}$ for adults.

For children, low systolic arterial blood pressure is defined as lower than $70 \mathrm{mmHg}$ for children 1 month to 1 year-old; lower than $(70 \mathrm{mmHg}+[2 x$ age]) from 1 to 10 years-old; and lower than $90 \mathrm{mmHg}$ for children 11 to 17 years-old. Modified from: Sampson HA et al. ${ }^{3}$ 
information. Emergency Rooms, public and private medical services, hospital admissions, appointments at allergists' offices are all valid databases, but with specific ways of organizing and compiling information. Given these differences in databases and methods used, it is not easy to compare and analyze the results presented in several studies published in this field. ${ }^{11} \mathrm{~A}$ systematic review was conducted recently to estimate the epidemiology of anaphylaxis in Europe. More than five thousand studies were analyzed, however, only 49 met the criteria for being valid to the comparison study, which described an incidence varying between 1,5 and 7,9 per 100.000 people per year in that continent. ${ }^{12}$

As it can be seen, there are many challenges regarding epidemiological studies on anaphylaxis. Beyond what has been presented, one needs to consider that the data of patients who have been admitted in emergency services and/or have been hospitalized, do not exactly indicate the incidence in a population, given that only patients who are registered in the system are being considered. Therefore, medical databases do not reflect the reality of prevalence in a given population, since some people do not ask for medical assistance during an anaphylactic reaction.

Another way to evaluate the prevalence of anaphylaxis is through self-injector epinephrine prescription. ${ }^{13}$ Unfortunately, this is impossible where this kind of medication is not available, as it is the case of Brazil.

Despite the methodological difficulties, it is estimated that 1 in 200 emergency medical appointments is due to hypersensitivity reactions, from mild urticaria to severe anaphylaxis. ${ }^{14}$ Besides, studies show that there are as many as 50 to 200 anaphylactic reactions for each 100.000 people, i.e., 2\% approximately of a given population may have had at least one episode in their lifetime. ${ }^{15}$

Another important aspect of epidemiologic studies refers to the increasing prevalence of the disease over time. Yocum et al. ${ }^{16}$ started an initiative called Rochester Epidemiology Project, which used medical records of the population from Omstead County (MN), in the period from 1983 to 1987 in order to evaluate this longitudinal perspective. This research was resumed by Decker et al. ${ }^{17}$ in the 1990's with an identical methodology, aiming to provide some further analysis. Thereby, it was possible to compare the anaphylaxis prevalence across a period of time, and it was clear that it is increasing, mainly among children and young adults. The level was raised from 21 to 49,8 per 100.000 residents. ${ }^{17}$ Of interest is a study in Wales (UK), where there was a fivefold increase in prevalence from 1994 to $1999 .{ }^{18}$ There are other studies also showing this trend, especially due to food reactions. ${ }^{19-21}$
Not only the prevalence, but also the severity of anaphylaxis has been increasing.

In the UK, hospital admissions due to this disease have increased among all age groups, going from 5 per million in the period of 1990-1991, to 36 per million in 2003-2004. ${ }^{22}$ A more recent study has observed that hospital admissions are still increasing in that region, and that the disease represents $0.1 \%$ of admissions in intensive care for children, and $0.3 \%$ for adults. ${ }^{23}$

In the USA, Lin et. al., ${ }^{24}$ observed that hospital admissions due to anaphylaxis in New York have increased from 17 to 42 per million of people in ages from zero to 20 years in the period of 1994 to 2005 . According to another study in Florida, the levels of emergencies caused by this disease were much lower than in northern American states (6-8/1000.000 approximately). ${ }^{25}$ This highlights the necessity of regional studies, in order to find out local factors that intervene, such as solar exposure which leads to higher levels of D-Vitamin. ${ }^{26}$

As mentioned above, among the causes for anaphylaxis, food allergies are the ones that contribute the most to the observed increase of the disease. Hospital admissions due to food allergies in Australia have increased more than 13\% in the decade from 1995 to 2005, especially among children under 5 years. During the same period, hospital admissions due to other kinds of anaphylaxis increased only by $8.5 \%$, with emphasis in adults above 35 years. ${ }^{27}$ It is curious to notice that this escalation in frequency and severity in food allergies and other types of anaphylaxis is happening simultaneously with an overall decrease in asthma, which has led many international societies on the field to create specific study-groups to approach this issue. ${ }^{28-30}$

Death caused by anaphylactic reactions is even harder to be estimated, given that there are no validated post-mortem exams to diagnose the problem. The only exception is the measurement of serum tryptase level, which quickly returns to normal parameters after the anaphylactic episode. Studies calculate that there are between 0.3 to 0.6 death/million people a year caused by anaphylaxis, and the most important etiologies are drugs, followed by insect venom and food. ${ }^{31,32}$ Another source indicates the lethality of anaphylaxis to be in order of $0.65-2 \% .{ }^{33}$ In hospitals and allergy clinics in Switzerland, levels of anaphylaxis varied between 7.9 and 9.6 cases/100,000 inhabitants, with 3 deaths registered. ${ }^{34}$ In Australia, there were 112 fatalities in the period of 1997 to 2005 and it was noticed that death caused by drugs had increased when compared to other causes, which remained stable. ${ }^{35}$ In Brazil, Tanno et. al. ${ }^{36}$ found a ratio of 0.87 death per million of people a year, level that is too low and probably affected by under notification. 
The triggers of anaphylaxis are also object of several epidemiological studies and vary according to the patient's age: children, teenagers and young adults are more vulnerable to food allergies, whereas elderly people are more prompt to be affected by medication, insects' venom and idiopathic anaphylaxis. ${ }^{37}$ The most common triggers vary according to the region and to some population's habits. In the USA, food products, particularly peanuts, are the main cause of anaphylaxis, followed by dried fruits, eggs and dairies for children; and sea food and fish for adults ${ }^{38}$. Several studies worldwide mention food products as the main etiologic agent for anaphylaxis. ${ }^{39-45}$ Food allergies are also related to a higher occurrence of anaphylaxis. ${ }^{46}$ Besides food per se, there are other substances contained in food products, which can be hard to identify, and may be the real cause of allergic reaction, such as mites, 47-49 parasites (Anisakis simplex), ${ }^{50}$ food additives, ${ }^{51}$ and foods that cross-react with other already identified products. ${ }^{52}$ Insect venoms, particularly those from the Hymenoptera class, are also an important cause of anaphylaxis. ${ }^{53}$ Whenever there is mastocytosis or mastocyte activation syndrome, the insect venom may lead to even worse reactions, which are harder to treat. ${ }^{54}$ Other causes of anaphylaxis are related to drugs such as: antibiotics (particularly beta-lactams ones), analgesics and anti-inflammatory medications, anesthesia medications and even apparently harmless substances such as folic acid and vitamins. ${ }^{55}$ Other examples of drugs causing severe reactions of hypersensitivity are monoclonal antibodies (cetuximab, infliximab and omalizumab);56-58 immunotherapy and allergy skin tests, ${ }^{59-60}$ infectious diseases prevention vaccines, or their excipients such as gelatin, dextran and egg traces, ${ }^{61}$ radiological contrast media, ${ }^{62}$ latex, ${ }^{63}$ cold, ${ }^{64}$ physical exercise, ${ }^{65}$ seminal fluid ${ }^{66}$ and many less common agents such as: glue, seeds, mold and cleaning products ${ }^{17,37}$. Finally, it has been recently described a new trigger of anaphylaxis occurring in patients with specific IgE antibody to galactose- $\alpha 1,3-$ galactose ( $\alpha-G a l)$, a carbohydrate present in non-primate mammalian proteins. Such patients may develop late anaphylaxis after eating red meat. ${ }^{67}$ Table 2 shows the main triggers of anaphylactic reactions. 68

Given the fact that sensitization depends on exposure to triggers as well as to genetic factors not yet fully understood, it is possible to assume that many regional allergen also not identified yet may be important to some groups of patients depending on their habits and exposure.

Beyond causal factors, there are other concomitant reasons that can be decisive for the occurrence and severity of the disease. They are:

- Allergy and atopy: allergic diseases poorly treated, particularly asthma, are one of the main risk factors for people who develop anaphylaxis, not only for patients with IgE dependent mechanisms, but also for those with non-IgE immunological reactions, e.g. radiologic contrasts and physical exercise. ${ }^{69-70}$

- Socio-economic factors: the incidence of anaphylaxis is higher in wealthier populations, which cannot be explained by their better access to medical services and health insurance systems. ${ }^{11}$

- Gender: despite having a higher incidence in male children, anaphylaxis generally affects more women than men, because progesterone increases both histamine release and sensitivity of the target organs to inflammatory cell mediators. ${ }^{71}$

- Age: it is hard to diagnose anaphylaxis in small children given their inability to express themselves properly. Teenagers are more likely to be exposed to different triggers, whilst elderly often use several medications. All these factors can enhance the risk of anaphylaxis. ${ }^{4}$

- Occupation: workers that are exposed to certain triggers can have a higher incidence of the disease, such as health professionals in case of anaphylaxis to latex. ${ }^{71}$

Some clinical conditions also interfere in a higher incidence and more severe forms of anaphylaxis, such as psychiatric diseases, thyroid dysfunctions, alcohol and drugs abuse, acute viruses, menses and emotional stresses. Others can be chronic diseases, particularly cardiovascular and respiratory ones and their treatment medication, such as beta-blockers and angiotensin converting enzyme inhibitors. ${ }^{72-74}$

It has been noticed that between 10 to $20 \%$ of anaphylactic patients may have biphasic reactions, characterized by a second manifestation generally 4 to 6 hours after the first one. ${ }^{75}$ However, this second occurrence can happen as late as 78 hours after the first manifestation.

One of the most intriguing questions refers to the relevant and predictive factors which can be used to foresee an anaphylactic reaction, and to determine the chances of a given patient to incur in a new episode.

Until nowadays, no test in vivo or in vitro was able to determine whether a patient will suffer an anaphylactic reaction. Neither the size of the papules in puncture allergic tests, nor serum IgE level corresponds directly to the severity or the prediction of an anaphylactic reaction. 76

Even though some individuals might have a higher likelihood to incur in an anaphylactic reaction (such as in mastocytosis or in cross-sensitivity reactions like fruitlatex syndrome) the safest and most efficient way to 
Table 2 - Causes of anaphylaxis

\section{Foods}

North America: cow's milk, egg, peanut, tree nuts and fish. Red meat (galactose alpha-1,3 galactose)

Europe: fruits

Middle East: sesame

Asia: wheat, chickpea, and rice

\section{Insects}

Stinging: Hymenoptera (Apidae and Vespidae) and Formicidae (ant)

Biting: kissing bugs, mosquitoes, and ticks

\section{Medications}

Antibiotics: penicillin, cephalosporins, and quinolones

Antiviral agents

Antifungal agents

NSAIDS*

Chemotherapeutics and biological agents

Oversulfated chondroitin sulfate in heparin

Vaccines (gelatin, egg)

\section{Mast cell disorders}

Mast cell activation syndrome

Mastocytosis

\section{Others}

Radiocontrast media and fluorescein dye

Perioperative agents: neuromuscular agents, antimicrobials, latex, opioids, colloid plasma expanders, protamine, chlorhexidine, and blood transfusions

Allergen skin testing and allergen-specific immunotherapy

Natural rubber latex

Seminal fluid

Airborne allergens (rare)

Idiopathic anaphylaxis

Exercise-induced (likely associated with concomitant food intake)

* NSAIDs = Nonsteroidal Anti-Inflammatory Drugs.

Modified from Samant SA et al. ${ }^{68}$

identify people under risk is through a well-documented history of a previous anaphylactic reaction. However, many patients do not have such a previous episode. Even atopy, which is a well-documented risk factor for the disease, is not linearly correlated with anaphylaxis, provided that there are much more atopic individuals without anaphylaxis than the opposite. ${ }^{76-77}$

In Brazil research on epidemiology of anaphylactic reactions are still scarce. Apparently, the etiologic agents do not differ much from those described in international studies, with medication, food and insects venom being the most common causes. ${ }^{40,78}$
There is a pressing need to further study this issue in our country, especially if one considers the restrictions imposed on those who suffer from this disease by not having access to carry self-injection epinephrine, a medication that is not yet available here.

Studying the patterns of anaphylaxis in our environment will certainly contribute to a better understanding of this disease, as well as to a clearer comprehension of regional differences in morbidity and mortality factors. Such research will also demonstrate the importance of continuing education to the medical class and the inclusion of this knowledge in the curriculum of all medical schools. 


\section{REFERENCES}

1. Joint Task Force of Practice Parameters. The diagnosis and management of anaphylaxis. J Allergy Clin Immunol. 1998; 101:S465-S528.

2. Sampson HA, Muñoz-Furlong A, Bock SA, Schmitt C, Bass R, Chowdhury BA, et al. Symposium on the Definition and Management of Anaphylaxis: Summary report. J Allergy Clin Immunol. 2005;115:584-91.

3. Sampson HA, Muñoz-Furlong A, Campbell RL, Adkinson NF Jr, Bock SA, Branum A, et al. Second symposium on the definition and management of anaphylaxis: Summary report - Second National Institute of Allergy and Infectious Disease/Food Allergy and Anaphylaxis Network Symposium. J Allergy Clin Immunol. 2006;117:391-7.

4. Simons FE, Ardusso LR, Bilò MB, Dimov V, Ebisawa M, El-Gamal YM, et al. 2012 Update: World Allergy Organization Guidelines for the assessment and management of anaphylaxis. Curr Opin Allergy Clin Immunol. 2012;12:389-99.

5. Simons FE, Ardusso LR, Bilò MB, Cardona V, Ebisawa M, El-Gamal YM, et al. International consensus on (ICON) anaphylaxis. World Allergy Organ J. 2014;7:9.

6. Campbell RL, Hagan JB, Manivannan V, Decker WW, Kanthala AR, Bellolio MF, et al. Evaluation of national institute of allergy and infectious diseases/food allergy and anaphylaxis network criteria for the diagnosis of anaphylaxis in emergency department patients. J Allergy Clin Immunol. 2012;129:748-52.

7. Samant SA, Campbell RL, Li JT. Anaphylaxis: diagnostic criteria and epidemiology. Allergy Asthma Proc. 2013;34:115-9.

8. Huang F, Chawla K, Järvinen KM, Nowak-Węgrzyn A. Anaphylaxis in a New York City pediatric emergency department: triggers, treatments, and outcomes. J Allergy Clin Immunol. 2012;129:162-8.

9. Harduar-Morano L, Simon MR, Watkins S, Blackmore C. Algorithm for the diagnosis of anaphylaxis and its validation using populationbased data on emergency department visits for anaphylaxis in Florida. J Allergy Clin Immunol. 2006;126:98-104.

10. O uso dos coeficientes, índices e razões e os indicadores de morbidade [site na Internet]. Disponível em: http://www.ee.usp. br/graduacao/ens435/modulo4/modulo4j.html (Acessado em 15/01/2014).

11. Lieberman P. Epidemiology of anaphylaxis. Curr Opin Allergy Clin Immunol. 2008;8:316-20.

12. Panesar SS, Javad S, de Silva D, Nwaru BI, Hickstein L, Muraro A, et al. The epidemiology of anaphylaxis in Europe: a systematic review. Allergy. 2013;68:1353-61.

13. Simons FER, Peterson S, Black CD. Epinephrine dispensing patterns for an out-of-hospital population: A novel approach to studying the epidemiology of anaphylaxis. J Allergy Clin Immunol. 2002;110:647-51.

14. Ben-Shoshan $M$, Clarke AE. Anaphylaxis: past, present and future. Allergy. 2011;66:1-14.

15. Simons FE. Anaphylaxis. J Allergy Clin Immunol. 2010;125:S161-81.

16. Yocum MW, Butterfield JH, Klein JS, Volcheck GW, Schroeder DR, Silverstein MD. Epidemiology of anaphylaxis in Olmsted County: A population-based study. J Allergy Clin Immunol. 1999;104:452-6.

17. DeckerWW, Campbell RL, Manivannan V, Luke A, Sauver St.JL, Weaver A, et al. The etiology and incidence of anaphylaxis in Rochester, Minnesota: A report from the Rochester Epidemiology Project. J Allergy Clin Immunol. 2008;122:1161-5.

18. Rangaraj S, Tuthill D, Burr M, Alfaham M. Childhood epidemiology of anaphylaxis and epinephrine prescriptions in Wales: 1994-1999. J Allergy Clin Immunol. 2002;109:S75

19. Lin RY, Anderson AS, Shah SN, Nurruzzaman F. Increasing anaphylaxis hospitalizations in the first 2 decades of life: New York State, 1990-2006. Ann Allergy Asthma Immunol. 2008;101:387-93.

20. Sheikh A, Cox JH, Newton J, Fenty J. Trends in national incidence, lifetime prevalence and adrenaline prescribing for anaphylaxis in England. J R Soc Med. 2008;101:139-43.
21. Poulos LM, Waters AM, Correll PK, Loblay RH, Marks GB. Trends in hospitalizations for anaphylaxis, angioedema, and urticaria in Australia, 1993-1994 to 2004-2005. J Allergy Clin Immunol. 2007;120:878-84.

22. Gupta R, Sheikh A, Strachan DP, Anderson HR. Time trends in allergic disorders in the UK. Thorax. 2007;62:91-6.

23. Gibbison B, Sheikh A, McShane P, Haddow C, Soar J. Anaphylaxis admissions to UK critical care units between 2005 and 2009. Anaesthesia. 2012;67:833-9.

24. Lin RY, Anderson AS, Shah SN, Nurruzzaman F. Increasing anaphylaxis hospitalizations in the first 2 decades of life: New York State, 1990-2006. Ann Allergy Asthma Immunol. 2008;101:387-93.

25. Harduar-Morano L, Simon MR, Watkins S, Blackmore C. Algorithm for the diagnosis of anaphylaxis and its validation using populationbased data on emergency department visits for anaphylaxis in Florida. J Allergy Clin Immunol. 2010;126:98-104.

26. Taback SP, Simons FE. Anaphylaxis and vitamin D: a role for the sunshine hormone? J Allergy Clin Immunol. 2007;120:128-30.

27. Poulos LM, Waters AM, Correll PK, Loblay RH, Marks GB. Trends in hospitalizations for anaphylaxis, angioedema, and urticaria in Australia, 1993-1994 to 2004-2005. J Allergy Clin Immunol. 2007;120:878-84.

28. Ross Anderson H, Gupta R, Strachan DP, Limb ES. Fifty years of asthma: UK trends from 1955-2004.Thorax. 2007:62:85-90.

29. Simons FE. Anaphylaxis, killer allergy: long-term management in the community. J Allergy Clin Immunol. 2006:117:367-77.

30. Warner JO. Anaphylaxis: the latest allergy epidemic. Pediatr Allergy Immunol. 2007;18:1-2.

31. Liew WK, Williamson E, Tang MLK. Anaphylaxis fatalities and admissions in Australia. J Allergy Clin Immunol. 2009;123:434-42.

32. Pumphrey RS, Gowland $\mathrm{MH}$. Further fatal allergic reactions to food in the United Kingdom, 1999-2006. J Allergy Clin Immunol. 2007;119:1018-9.

33. Moneret-Vautrin DA, Morisset M, Flabbee J, Beaudouin E, Kanny G. Epidemiology of life-threatening and lethal anaphylaxis: a review. Allergy. 2005;60:443-51.

34. Helbling A, Hurni T, Mueller UR, Pichler WJ. Incidence of anaphylaxis with circulatory symptoms: a study over a 3-year period comprising 940,000 inhabitants of the Swiss Canton Bern. Clin Exp Allergy. 2004;34:285-90.

35. Liew WK, Williamson E, Tang ML. Anaphylaxis fatalities and admissions in Australia. J Allergy Clin Immunol. 2009;123:434-42.

36. Tanno LK, Ganem F, Demoly P, Toscano CM, Bierrenbach AL. Undernotification of anaphylaxis deaths in Brazil due to difficult coding under the ICD-10. Allergy. 2012;67:783-9.

37. Simons FER. Anaphylaxis: Recent advances in assessment and treatment. J Allergy Clin Immunol. 2009;124:625-36.

38. Sampson HA, Mendelson L, Rosen JP. Fatal and near-fatal anaphylactic reactions to food in children and adolescents. $\mathrm{N} \mathrm{Engl}$ J Med. 1992;6:327-80.

39. Hoffer V, Scheuerman O, Marcus N, Levy Y, Segal N, Lagovsky I, et al. Anaphylaxis in Israel: experience with 92 hospitalized children. Pediatr Allergy Immunol. 2011;22:172-7.

40. Sole D, Ivancevich JC, Borges MS, Coelho MA, Rosario NA, Ardusso $L R$, et al. Anaphylaxis in Latin America: a report of the online Latin American survey on anaphylaxis (OLASA). Clinics (Sao Paulo). 2011;66:943-7.

41. DeSwert LF, Bullens D, Raes M, Dermaux AM. Anaphylaxis in referred pediatric patients: demographic and clinical features, triggers, and therapeutic approach. Eur J Pediatr. 2008;167:1251-61.

42. Orhan F, Canitez Y, Bakirtas A, Yilmaz O, Boz AB, Can D, et al. Anaphylaxis in Turkish children: a multi-centre, retrospective, case study. Clin Exp Allergy. 2011;41:1767-76.

43. Mullins RJ. Anaphylaxis: risk factors for recurrence. Clin Exp Allergy. 2003;33:1033-40.

44. Smit DV, Cameron PA, Rainer TH. Anaphylaxis presentations to an emergency department in Hong Kong: incidence and predictors of biphasic reactions. J Emerg Med. 2005;28:381-8. 
45. Moro Moro M, Tejedor Alonso MA, Esteban Hernández J, Múgica García MV, Rosado Ingelmo A, Vila Albelda C. Incidence of anaphylaxis and subtypes of anaphylaxis in a general hospital emergency department. J Investig Allergol Clin Immunol. 2011;21:142-9.

46. Cianferoni A, Novembre E, Pucci N, Lombardi E, Bernardini R, Vierucci A. Anaphylaxis: a 7-year follow-up survey of 46 children. Ann Allergy Asthma Immunol. 2004;92:464-8.

47. Guerra Bernd LA, Arruda LK, Barros Antunes HB. Oral anaphylaxis to mites. Allergy. 2001;56:83-4.

48. Geller M, Ludwig Hahnstadt R, Malheiros Rego R, Fernandez-Caldas E. Anafilaxia induzida por farinha de trigo contaminada por ácaros. Rev Bras Alerg Imunopatol. 2009;32:199-201.

49. Sánchez-Borges M, Iraola V, Fernández-Caldas E, Capriles-Hulett A, Caballero-Fonseca F. Dust mite ingestion-associated, exerciseinduced anaphylaxis. J Allergy Clin Immunol. 2007;120:714-6.

50. Audicana MT, Kennedy MW. Anisakis simplex: from obscure infectious worm to inducer of immune hypersensitivity. Clin Microbiol Rev. 2008;21:360-79.

51. Ohgiya Y, Arakawa F, Akiyama H, Yoshioka Y, Hayashi Y, Sakai S, et al. Molecular cloning, expression, and characterization of a major 38-kd cochineal allergen. J Allergy Clin Immunol. 2009;123:1157-62.

52. Sampson HA, Burks AW. Adverse reactions to foods. In: Adkinson NF, Busse W, Bochner B, Holgate S, Simons FE, Lemanske Jr R. Middleton's Allergy: Principles and Practice. Michigan: Elsevier; 2009. p. 1139-67.

53. Castro FFM, Palma MS. Alergia a Venenos de Insetos. $1^{\text {a }}$ ed. São Paulo: Manole Editora Ltda.; 2009.

54. Bonadonna P, Zanotti R, Müller U. Mastocytosis and insect venom allergy. Curr Opin Allergy Clin Immunol. 2010;10:347-53.

55. Rubio M, Bousquet PJ, Demoly P, Chung CH, Mirakhur B, Chan E, et al. Update in drug allergy: novel drugs with novel reaction patterns. Curr Opin Allergy Clin Immunol. 2010;10:457-62.

56. Chung $\mathrm{CH}$, Mirakhur B, Chan E, Le QT, Berlin J, Morse M, et al. Cetuximab- induced anaphylaxis and IgE specific for galactosealpha-1,3-galactose. N Engl J Med. 2008;358:1109-17.

57. Cheifetz A, Smedley M, Martin S, Reiter M, Leone G, Mayer L, et al. The incidence and management of infusion reactions to infliximab: a large center experience. Am J Gastroenterol. 2003;98:1315-24.

58. Limb SL, Starke PR, Lee CE, Chowdhury BA. Delayed onset and protracted progression of anaphylaxis after omalizumab administration in patients with asthma. J Allergy Clin Immunol. 2007;120:1378-81.

59. Rezvani M, Bernstein DI. Anaphylactic reactions during immunotherapy. Immunol Allergy Clin North Am. 2007;27:295-307.

60. Rodriguez-Perez N, Ambriz MM, Canonica GW, Penagos M. Frequency of acute systemic reactions in patients with allergic rhinitis and asthma treated with sublingual immunotherapy. Ann Allergy Asthma Immunol. 2008;101:304-10.
61. Kelso JM, Li JT, Nicklas RA, Bernstein DI, Blessing-Moore J, Cox L, et al. Adverse reactions to vaccines. Ann Allergy Asthma Immunol. 2009;103:1-14.

62. Brockow K, Romano A, Aberer W, Bircher AJ, Barbaud A, Bonadonna $P$, et al. Skin testing in patients with hypersensitivity reactions to iodinated contrast media - a European multicenter study. Allergy. 2009;64:234-41.

63. YungingerJW. Natural rubber latexallergy. In: Adkinson NF, BusseW, Bochner B, HolgateS, Simons FE, LemanskeJr R. Middleton's Allergy: Principles and Practice. Michigan: Elsevier; 2009. p.1019-26.

64. BoyceJA. Successful treatment of cold-induced urticaria/anaphylaxis with anti-IgE. J Allergy Clin Immunol. 2006;117:1415-8.

65. Barg W, Medrala W, Wolanczyk MA. Exercise-Induced Anaphylaxis: An Update on Diagnosis and Treatment. Curr Allergy Asthma Rep. 2011;11:45-51.

66. Basagana M, Bartolome B, Pastor C, Torres F, Alonso R, Vivanco $F$, et al. Allergy to human seminal fluid: cross-reactivity with dog dander. J Allergy Clin Immunol. 2008;121:233-39.

67. Commins SP, Satinover SM, Hosen J, Mozena J, Borish L, Lewis BD, et al. Delayed anaphylaxis, angioedema, or urticaria after consumption of red meat in patients with IgE antibodies specific for galactose-a1,3-galactose. J Allergy Clin Immunol. 2009;123:426-33.

68. Samant SA, Campbell RL, Li JT. Anaphylaxis: diagnostic criteria and epidemiology. Allergy Asthma Proc. 2013;34:115-9.

69. Iribarren C, Tolstykh IV, Miller MK, Eisner MD. Asthma and the prospective risk of anaphylactic shock and other allergy diagnoses in a large integrated health care delivery system. Ann Allergy Asthma Immunol. 2010;104:371-7.

70. Fallon PG, Emson CL, Smith P, McKenzie ANJ. IL-13 overexpression predisposes to anaphylaxis following antigen sensitization. J Immunol. 2001;166:2712-6.

71. Lieberman P, KempSF, Oppenheimer J, Lang DM, Bernstein L, Nicklas RA. The diagnosis and management of anaphylaxis: An updated practice parameter. J Allergy Clin Immunol. 2005;115:483-524.

72. Greenberger PA, Rotskoff BD, Lifschultz B. Fatal anaphylaxis: postmortem findings and associated comorbid diseases. Ann Allergy Asthma Immunol. 2007;98:252-7.

73. Mueller UR. Cardiovascular disease and anaphylaxis. Curr Opin Allergy Clin Immunol. 2007;7:337-41.

74. Mullins RJ. Anaphylaxis: risk factors for recurrence. Clin Exp Allergy. 2003;33:1033-40.

75. Ellis AK. Biphasic Anaphylaxis: A Review of the Incidence, Characteristics and Predictors. Open Allergy J. 2010;3:24-8.

76. Tang MLK, Osborne N, Allen K. Epidemiology of anaphylaxis. Cur Opin Allergy Clin Immunol. 2009;9:351-6.

77. de Silva IL, Mehr SS, Tey D, Tang ML. Paediatric anaphylaxis: a 5 year retrospective review. Allergy. 2008;63:1071-6.

78. Bernd LAG, Fleig F, Alves MB, Bertozzo R, Coelho M, Correia J, et al. Anafilaxia no Brasil - Levantamento da ASBAI. Rev Bras Alerg Imunopatol. 2010;33:190-8. 